\title{
Poem
}

\section{Would you do anything differently?}

\author{
Ivory Tifa ${ }^{\mathrm{a}, \mathrm{b}}$ \\ ${ }^{a}$ Kaiser Permanente, Granada Hills, CA, USA \\ ${ }^{\mathrm{b}}$ Boston University College of Health \& Rehabilitation Sciences, Boston, MA, USA \\ E-mail: ivorytifa@gmail.com
}

They say, put your own oxygen mask on first and then help the person seated next to you

But what if there was a mask that breathes life into both of us simultaneously

What if I gift to you my last dying breath and just the act of giving

breathes life back into my own lungs,

near collapsed and deflated

What if by lighting your fire

my flame grew brighter

like a mirror to a flame in the desert

What if our bodies forgot which heartbeat was which as you held my hand and pulled me up,

your own heart growing stronger in the process

What if adolescent boys in inner city schools

who witnessed community violence

but managed to help others

therefore had less aggressive behavior,

the mirror in the school bathroom reflecting back to

them

their strength, power and compassion

What if refugees from war torn countries ached a little less for their homeland

as they extended a hand to other refugees who arrived on the shores of Australia

their outstretched hand a welcoming somehow reaching out to their own former selves in the process

What if I am not without you and you are not without me What if I am in you and you are in me and it is impossible for me to pour into you without pouring back into myself

What if helping you fly gives me wings

like women with MS who became stronger just by providing a compassionate phone call to another

What if just writing a card to a friend in need could reduce spikes in your blood pressure under stress

and reduce the stress hormones in your saliva

What if you lifted a friend in need and that lifted you What if the Yankees batting average soared every year when they visited the children's hospital pouring an infusion of caring into the children which looped back to them

like an ECMO machine, warming and oxygenating their blood

and putting it back into their bodies, allowing them to be even more capable 
What if just helping a neighbor helped college students cope as they stood in the dust of the Christchurch mosque terrorist attacks in New Zealand

and what if even the mere intention of helping someone else in the future

led to greater happiness

and what if even having helped someone in the past did too

as though caring for others was a drug that did not know the limits of time

What if volunteering weekly brought the equivalent change in happiness

of moving from an income bracket of less than $\$ 20,000$

to a bracket of $\$ 75-100,000$, as though love were a currency more powerful than money

What if we had not within ourselves individually, but within the connections and interactions between us

an untapped tool for healing

What if helping others was a public health intervention?

What if all of this was true?

Would you do anything differently?

\section{Author bio}

Ivory is an occupational therapist and poet. She grew up in Van Zandt, Washington and has lived in several cities and countries before settling in the greater Los Angeles area. She has always been drawn to the healing and care of others. Ivory holds a Master of Arts in Occupational Therapy from New York University where she was awarded the Arch Award in recognition for excellence in service. She is currently a doctoral candidate at Boston University. Her doctoral project in occupational therapy is focused on the healing power of kindness and altruism for people who have experienced trauma. Simultaneously, she is producing a documentary about the healing power of helping others with award winning director Assaf Ben Shetrit. 